\title{
RESVERATROL ATTENUATES OXIDATIVE STRESS IN CHEMOTHERAPY INDUCED ACUTE KIDNEY INJURY: AN EXPERIMENTAL RAT MODEL
}

\section{Kumayl Abbas Meghji', Rizwan Ali Talpur', Arsalan Ahmed Uqaili ${ }^{\otimes I}$, Yar Muhammad Nizammani', Navaid Kazi', Ghulam Shah Nizammani}

\begin{abstract}
OBJECTIVE: To investigate the anti-oxidative and anti-nephrotoxic effects of resveratrol in cisplatin induced nephrotoxic albino Wistar rats.
\end{abstract}

METHODS: This quasi-experimental study was performed at Isra University, Hyderabad, Pakistan. Thirty male albino Wistar rats were divided into three groups: group-A (control), group-B (cisplatin) and group-C (cisplatin + resveratrol). Biochemical [serum urea, creatinine and glutathione peroxidase (GPX)] and renal histomorphology was performed in all groups after $2 \mathrm{I}$ days of treatment.

RESULTS: Difference in mean pre- and post-experimental body weight was observed in all three groups. Mean body weight decreased from $241.7 \pm 8.5 \mathrm{gm}$ to $196.50 \pm 9.34 \mathrm{gm}$ and from $237 \pm 7.4 \mathrm{gm}$ to $207.2 \pm 6.56 \mathrm{gm}$ in group-B and group- $C$ respectively. In group-A; mean serum urea was $22.7 \pm 2.66 \mathrm{mg} / \mathrm{dl}$, serum creatinine was $0.45 \pm 0.05 \mathrm{mg} / \mathrm{dl}$ and serum GPX was $1.44 \pm 0.13 \mathrm{ng} / \mathrm{ml}$. In group-B; mean serum urea level was $5 \mathrm{I} \pm 3.65 \mathrm{mg} / \mathrm{dl}$, mean serum creatinine was $0.78 \pm 0.05 \mathrm{mg} / \mathrm{dl}$ and serum GPX was $0.85 \pm 0.1 \mathrm{I} \mathrm{ng} / \mathrm{ml}$. In group-C, mean serum urea level was $32.8 \pm \mathrm{I} .45 \mathrm{mg} / \mathrm{dl}$, serum creatinine level was $0.4 \mathrm{I} \pm 0.09$ $\mathrm{mg} / \mathrm{dl}$ and serum GPX was $1.53 \pm 0.08 \mathrm{ng} / \mathrm{ml}$. In group-A, renal structure was intact, marked changes were observed in renal histology of group-B while group- $C$ displayed less glomerular damage. The mean distance between visceral and parietal layers of Bowman's capsule was $69.34 \pm 0.87 \mu \mathrm{m}$ in groupA, $216.5 \pm 1.32 \mu \mathrm{m}$ in group-B while $102.22 \pm 1.65 \mu \mathrm{m}$ in group-C. Areas of peritubular fibrosis and congestion were observed in groups $B$ and $C$ but less prominent in group- $C$ compared with group- $B$.

CONCLUSION: Resveratrol therapy is a potent anti-nephrotoxic regime showing promising results in chemotherapy induced nephrotoxicity and oxidative stress.

KEY WORDS: Resveratrol (MeSH); Cisplatin (MeSH); Oxidative Stress (MeSH); Antioxidants (MeSH); Glutathione Peroxidase (MeSH).

THIS ARTICLE MAY BE CITED AS: Meghji KA, Talpur RA, Uqaili AA, Nizammani YM, Kazi N, Nizammani GS. Resveratrol attenuates oxidative stress in chemotherapy induced acute kidney injury: an experimental rat model. Khyber Med Univ J 20 I9; I (2):85-9. DOI: I0.35845/kmuj.2019.19। I4

\section{INTRODUCTION}

1 he new consensus term for acute renal failure (ARF) is acute kidney

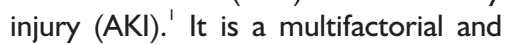
multi-phasic clinical syndrome. $\mathrm{AKI}$ is a sudden occurrence of kidney damage or failure that causes not only the reduction of renal function, but also the build-up of metabolic wastes, such as creatinine and urea in the blood. This makes it hard for kidneys to keep the right balance of fluid within a body and can thus cause abnormal or reduced
I. Department of Physiology, Isra University, Hyderabad, Pakistan.

Email ${ }^{凶}$ : arsalanuqaili@gmail.com Contact \#: $\quad$ +92-333275570I

2. Department of Pathology, Isra University, Hyderabad, Pakistan

$\begin{array}{ll}\text { Date Submitted: } & \text { March 14, 2019 } \\ \text { Date Revised: } & \text { May 16, 2019 } \\ \text { Date Accepted: } & \text { May 21, 2019 }\end{array}$

urine output. ${ }^{2}$ In addition, some other common clinical symptoms include reduced output of urine leading to a disturbance in the concentration of not only metabolic acids, but also in the levels of important ions such as phosphate and potassium. ${ }^{3}$

Although incidence rates vary from population to population, in United States of America, taking a population of I million people, more than 5000 cases/year are reported that do not require dialysis and approximately 295 cases/year that require this mode of treatment. ${ }^{4} \mathrm{AKI}$ is highly prevalent in patients that are critically ill. The frequency of $\mathrm{AKI}$ in hospital inpatients is $1.9 \%{ }^{5}$ however this frequency is seen to rise almost above $40 \%$ when the patient is admitted to the ICU and is concomitantly suffering from sepsis. ${ }^{6}$ One out of 5 people suffer from AKI during their stay in the hospital which is directly related to an increased risk of morbidity and mortality (up to $30 \%$ ), particularly when dialysis becomes necessary. ${ }^{7}$ Mild to moderate decrease in renal function is also related to longer stay in hospital, higher treatment expense and considerably higher chance of developing chronic renal disease. $^{8}$

Although the underlying cause of $\mathrm{AKI}$, in most cases, is multi-factorial such as hypoperfusion / ischemia, sepsis etc., data from recent epidemiological studies has shown that nephrotoxic drugs, such as chemotherapy agents like cisplatin, are responsible for 19-25\% of AKI cases.' Despite being one of the most efficacious anti-cancer drugs used against a wide variety of solid tumors, cisplatin therapy is limited owing to the fact that it is notoriously toxic to the kidneys, causing $\mathrm{AKI}$ in 25-35\% of patients after administration of a single 


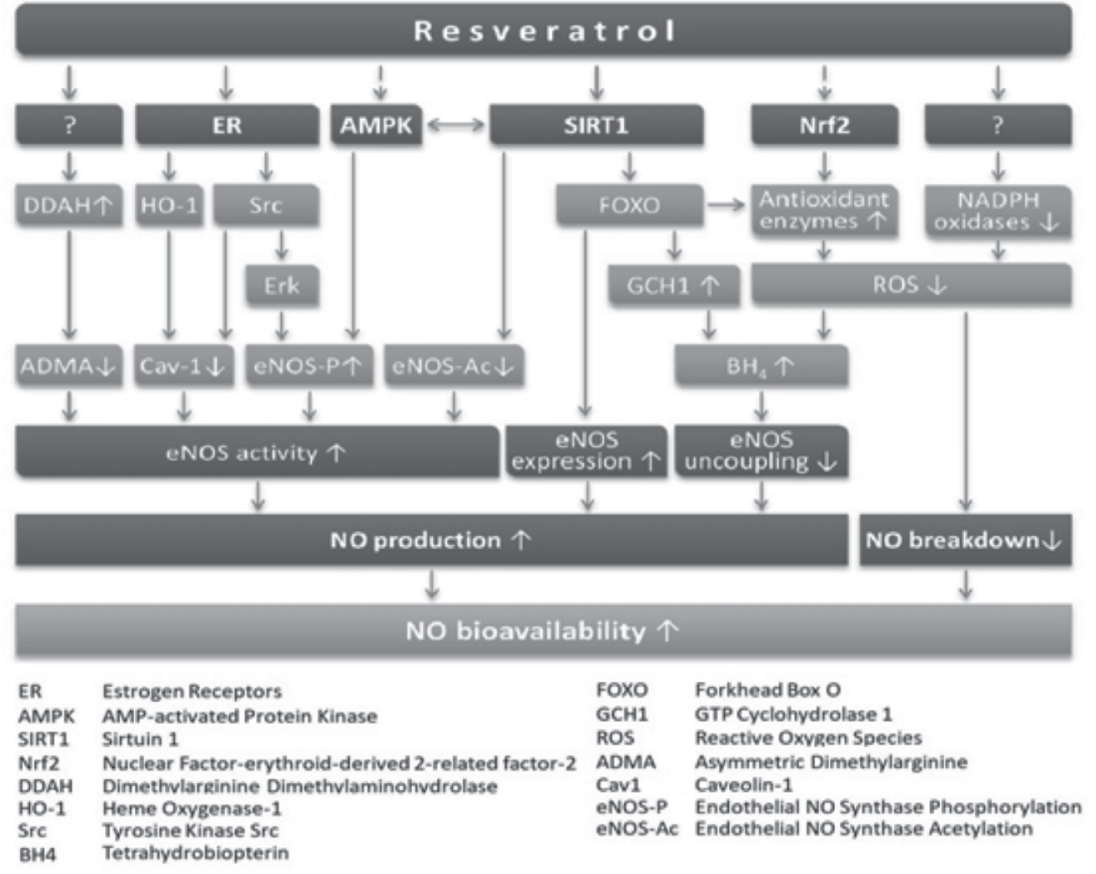

Figure I: Targets and actions of resveratrol ${ }^{15}$

dose. $^{10}$ The nephrotoxic nature of cisplatin is due to its reactive oxygen species (ROS) generating capability that causes depletion of glutathione levels and inhibition of renal antioxidant enzymes, causing AKI even with plausible reno-protective strategies such as co-administration with hydration." Therefore, the prediction and prevention of cisplatin induced AKI remains a challenge.

Resveratrol (trans-3,4',5trihydroxystilbene) (RSV) is a polyhydroxyphenol plant toxin (phytoalexin) present in several eatable plants, including grapes, raspberries and plums etc. $^{12}$ Due to its potent antiinflammatory as well as antioxidant potential, in recent years, there has been a general consensus regarding the positive effects of RSV, leading the usage of this drug for the prevention and treatment of various disease conditions. ${ }^{13}$ Endothelial nitric oxide synthase (eNOS) has been proposed as one of the possible targets responsible for the actions of RSV. ${ }^{14}$ RSV has also been found to simultaneously restrain production of ROS. The targets and actions of RSV are summarized in Figure I.

The main objective of present study was mixed into the diet which was fed to the animals orally for 21 days ( 3 weeks). The level of the orally administered dosage of RSV (10 mg/kg body weight) and intraperitoneal dose of cisplatin (cisplatin $20 \mathrm{mg} / \mathrm{kg}$ body weight intraperitoneally) was based on the previous works. ${ }^{16,17}$ Experimental work was conducted as per rules maintained by Ethical Committee of Isra University, Hyderabad, Pakistan. Body weights of all group rats were recorded before and after the experiment.

The experimental animals were anesthetized by placing them in an inverted glass jar containing cotton pieces soaked in chloroform. Blood samples were collected by cardiac puncture and transferred to gel tubes where they were allowed to stand for half an hour and then centrifuged at $3000 \mathrm{rpm}$ for $15 \mathrm{~min}$ at $4^{\circ} \mathrm{C}$ to separate serum which was stored for the different biochemical measurements. The animals of all groups were sacrificed by cervical dislocation. Skin incision was given from suprasternal notch to the lower half of abdomen. The kidneys were dissected out and fixed immediately in 10\% neutral formalin. Tissue was embedded in paraffin wax and 4-micron thick sections were obtained by microtome and stained with Hemtoxylin and Eosin ( $H$ \& $E)$ staining for histopathological analysis.

(healthy male albino Wistar selected by purposive sampling. The inclusion criteria was set as, rats having body weight of 200 to $300 \mathrm{gm}$, free from any co-morbidities and male rats, whereas exclusion criteria was set as rats having body weight less than 200 or more than $300 \mathrm{gm}$, female rats and moribund rats. After allowing the animals to acclimatize for one week, they were divided into 3 groups ( 10 rats per group) by simple random method; Group A (control rats), Group B (single dose of cisplatin $20 \mathrm{mg} / \mathrm{kg}$ body weight intraperitoneally), Group C (single dose of cisplatin $20 \mathrm{mg} / \mathrm{kg}$ body weight intraperitoneally + resveratrol 10 $\mathrm{mg} / \mathrm{kg}$ body weight orally), and kept in stainless steel cages under standard conditions of illumination with a 12 hours light-dark cycle at $25 \pm 1^{\circ} \mathrm{C}$. They were provided with normal chow diet and water ad libitum. Nephrotoxicity was induced by single intraperitoneal dose of cisplatin $20 \mathrm{mg} / \mathrm{kg}$ body weight. RSV was crushed into powder and
Serum urea and creatinine were analyzed on Hitachi Roche automated analyzer (Cobas $\mathrm{c} 3 \mathrm{II}$ ) whereas serum glutathione peroxidase (GPX) was analyzed using bioassay technology ELISA kit (catalogue no: EI242Ra) on DiaSource ELISA plate reader (RT093III7DIA) at Diagnostic Laboratory, Isra University, Hyderabad.

SPSS (Statistical Packages for Social Sciences) version 22.0 was used for data analysis. The statistical analysis of the differences of various quantitative variables between the experimental and control groups was evaluated by one way analysis of variance (ANOVA) followed by post hoc Tukey's test. P value $\leq 0.05$ was taken as statistically significant.

\section{RESULTS}

Pre-experimental body weight 
TABLE I: DIFFERENCE IN BODY WEIGHT BETWEEN EXPERIMENTAL GROUPS BY POST-HOC TUKEY TEST

\begin{tabular}{|c|c|c|c|}
\hline \multicolumn{2}{|c|}{ Groups } & Mean diff. & P-Value \\
\hline \multirow{2}{*}{ Group A } & Group B & -52.8 & 0.000 I \\
\cline { 2 - 4 } & Group C & -42.1 & 0.000 I \\
\hline Group B & Group C & 10.7 & 0.001 \\
\hline
\end{tabular}

TABLE II: MULTIPLE COMPARISON OF SERUM UREA AND SERUM CREATININE LEVELS BETWEEN GROUPS BY POST-HOC TUKEY TEST

\begin{tabular}{|c|c|c|c|c|}
\hline Parameter & \multicolumn{2}{|c|}{ Groups } & Mean diff. & P-Value \\
\hline \multirow{3}{*}{ Serum Urea } & \multirow{2}{*}{ Group A } & Group B & 28.3 & 0.005 \\
\hline & & Group C & 10.1 & 0.0001 \\
\hline & Group B & Group C & 18.2 & 0.0001 \\
\hline \multirow{3}{*}{$\begin{array}{l}\text { Serum } \\
\text { Creatinine }\end{array}$} & \multirow{2}{*}{ Group A } & Group B & 0.33 & 0.0001 \\
\hline & & Group C & 0.04 & 0.502 \\
\hline & Group B & Group C & 0.37 & 0.0001 \\
\hline
\end{tabular}

TABLE III: MULTIPLE COMPARISON OF SERUM GLUTATHIONE PEROXIDASE BETWEEN GROUPS BY POST-HOC TUKEY TEST

\begin{tabular}{|c|c|c|c|}
\hline \multicolumn{2}{|c|}{ Groups } & Mean diff. & P-Value \\
\hline \multirow{2}{*}{ Group A } & Group B & 0.59 & 0.000 I \\
\cline { 2 - 4 } & Group C & 0.09 & 0.172 \\
\hline Group B & Group C & 0.68 & 0.000 I \\
\hline
\end{tabular}

(mean \pm SD) of group $A, B$ and $C$ was $239.3 \pm 5.7 \mathrm{gm}, 241.7 \pm 8.5 \mathrm{gm}$ and $237 \pm 7.4 \mathrm{gm}$ respectively. At the end of the study duration, the body weights of group $A, B$ and $C$ were again measured. Significant difference in mean post experimental body weight was observed in all three groups i.e. in group A there was a rise in body weight $(249.30 \pm 6.27 \mathrm{gm})$ while in group B significant decline in mean body weight $(196.50 \pm 9.34 \mathrm{gm})$ and in group $\mathrm{C}$ a similar decline was also observed (207.2 $\pm 6.56 \mathrm{gm})$, however, the weight loss was not as much as seen in group $B$. There was a statistically significant difference ( $p$-value $<0.05$ ) between the experimental groups (Table l).

Post experimental biochemical analysis of all three groups was performed. In group $A$ the mean level of serum urea was $22.7 \pm 2.66 \mathrm{mg} / \mathrm{dl}$, serum creatinine was $0.45 \pm 0.05 \mathrm{mg} / \mathrm{dl}$ and serum GPX was $1.44 \pm 0.13 \mathrm{ng} / \mathrm{ml}$. In group $B$ the mean serum urea level was $5 \mathrm{I} \pm 3.65 \mathrm{mg} / \mathrm{dl}$, mean serum creatinine level was $0.78 \pm 0.05 \mathrm{mg} / \mathrm{dl}$ and serum GPX was $0.85 \pm 0.1 \mathrm{Ing} / \mathrm{ml}$. In group C the mean serum urea level was $32.8 \pm \mathrm{I} .45 \mathrm{mg} / \mathrm{dl}$, mean serum creatinine level was $0.4 I \pm 0.09$ and serum GPX was I.53 $\pm 0.08 \mathrm{ng} / \mathrm{ml}$. Post hoc analysis revealed that serum urea and creatinine levels were significantly high in cisplatin group (group B) compared to control (group A) and resveratrol group (group C) (Table II). Similarly, statistically significant decline in serum GPX levels in group B compared to group A and C (Table III).

Histopathological alterations in renal sections are shown in Figure 2. The distances between the visceral and parietal layers of Bowman's capsule were observed. In control group (group A), renal structure was intact and no change in renal histology was found. The mean distance between visceral and parietal layers of Bowman's capsule was $69.34 \pm 0.87 \mu \mathrm{m}$ whereas; in group $B$ (cisplatin) marked changes in renal histology were observed. Glomerular structure shrinkage was prominent with the mean distance between the visceral and parietal layers of Bowman's capsule $216.5 \pm 1.32 \mu \mathrm{m}$. However, resveratrol receiving (group C) displayed less glomerular damage with the mean distance between the visceral and parietal layers of Bowman's capsule
$102.22 \pm \mathrm{I} .65 \mu \mathrm{m}$ as compared with cisplatin group (group B).

In addition, areas of peritubular fibrosis and congestion were observed in $B$ and $C$ group but less prominent in group- $C$ compared with group-B.

\section{DISCUSSION}

The present study sought to investigate whether resveratrol exerted a renoprotective effect on cisplatin-induced $\mathrm{AKI}$ in a rat model by investigating various blood and histopathological parameters associated with renal function of nephrotoxic and treated rats. Our results revealed considerable decline in renal function as well as alterations in renal histological architecture after cisplatin administration. However, resveratrol co-treatment was associated with marked improvement of renal function causing significant reduction in serum creatinine and urea levels, increased glutathione peroxidase levels as well as improving the renal histological architecture. These findings show that resveratrol caused amelioration of nephrotoxicity produced by cisplatin administration by enhancing plasma anti-oxidant levels.

Being the waste disposal plants of the body, the kidneys are exposed to high quantities of toxic substances that make them prone to release substantial amounts of ROS. These free radicals ultimately lead to oxidative stress that has been attributed to the pathogenesis of renal damage. ${ }^{18}$ Cisplatin is known to deplete plasma level of endogenous antioxidants such as cysteine-rich proteins, glutathione and/or methionine, weakening the body's antioxidant defense machinery and ultimately leading to oxidative stress. ${ }^{19}$

As a polyphenolic phytoalexin, resveratrol has been reported to be beneficial for the prevention of numerous types of kidney diseases such as those caused by diabetes ${ }^{20}$, various harmful drugs, sepsis ${ }^{21}$ and ischemiareperfusion renal injuries. ${ }^{22,23}$ Consistent with these observations, the results of this current study show the positive effects of resveratrol in the prevention of renal damage and dysfunction as 

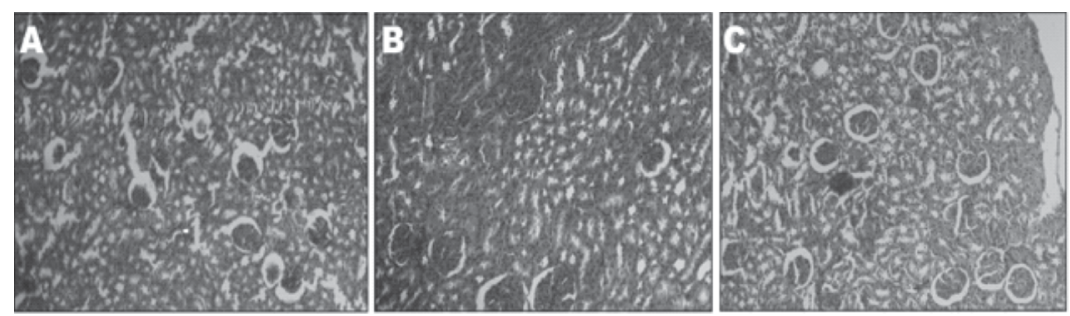

Figure 2: Evaluation of renal damage in experimental animals (100x Magnification) A - Control group showing normal glomerular and tubular architecture. B - Nephrotoxic group showing shrinkage of glomeruli, dilatation of bowmans slit and congestion. C - Resveratrol group showing near normal glomerular structure and comparatively much less apparent renal congestion.

concluded from decreased blood urea levels, decreased serum creatinine levels and increased anti-oxidant levels.

The results of this study are in accordance with the findings of various previous studies, which have proven that resveratrol is a potent anti-oxidant as well as a scavenger of ROS such as peroxides, and hydroxyl radicals. ${ }^{23}$ Similar findings were also reported in a recent study by Kitada, et al. ${ }^{16}$ in which resveratrol was found to cause marked reduction in urinary levels of albumin, histological mesangial expansion as well as renal levels of oxidative and inflammatory markers through the scavenging of ROS and normalizing manganese superoxide dismutase (MnSOD) function.

Similarly, like previous studies by Osman, et al. ${ }^{19}$ and Al Dera, et al. ${ }^{14}$, resveratrol showed to have protective effects on renal histology as resveratrol group showed near normal renal architecture. In addition, Chen, et al. ${ }^{24}$ reported that RSV therapy was able to alleviate symptoms of diabetic nephropathy induced by Streptozocin as it caused reduction in albuminuria, overall hypertrophy of the glomeruli as well as thickness of the glomerular basement membrane. It caused lowered transforming growth factor and nephrin expression in the renal tissues. Moreover, Wu, et al. $^{25}$ also confirmed that RSV has a nephroprotective effect by regulating the Sirtuin-I/Forkhead Box O (SIRTI/FOXOI) pathway causing increased expression of eNOS and leading to increase in Nitric oxide (NO) bioavailability.

With strengths, there were certain limitations in our study. There was limited time and funds availability due to which certain laboratory tests such as urine analysis, plasma albumin levels and plasma levels of inflammatory markers could not be performed. Therefore, further studies are recommended to assess the various effects of resveratrol on other blood and urine parameters as well as on other organs and to explore the effects of resveratrol in combination with other anti-nephrotoxic agents such as L-arginine and ascorbic acid etc.

\section{CONCLUSION}

This study showed a protective effect of resveratrol against cisplatin induced renal damage. Reduction of oxidative stress may be considered as one of the main pathways of action.

\section{REFERENCES}

I. Bellomo R. Acute Dialysis Quality Initiative workgroup. Acute renal failure-definition, outcome measures, animal models, fluid therapy and information technology needs: the Second International Consensus Conference of the Acute Dialysis Quality Initiative (ADQI) Group. Crit Care 2004;8:R204-12. DOI: I0.I I86/cc2872

2. Linkermann A, Chen G, Dong G, Kunzendorf U, Krautwald S, Dong Z. Regulated cell death in AKI. Clin J Am Soc Nephrol 2014 I;25(I2): 2689-70I. DOI: 10.168I/ASN. 2014030262

3. Bellomo R, Kellum JA, Ronco C. Acute kidney injury. Lancet 2012 31;380(9843):756-66. DOI: I0.1016/S0I40-6736(II)6I454-2

4. Hsu CY, McCullough CE, Fan D, Ordonez JD, Cherow GM, Go AS. Community-based incidence of acute renal failure. Kidney Int
2007;72(2):208-I2. DOI: 10.1038/sj.ki.5002297

5. Liangos $O$, Wald R, O'Bell JW, Price $L$, Pereira $B J$, Jaber $B L$. Epidemiology and outcomes of acute renal failure in hospitalized patients: a national survey. Clin J Am Soc Nephrol 2006; I (I):43-5I. DOI: 10.22I5/CJN.00220605

6. Bagshaw SM, George C, Bellomo R, and the ANZICS Database Management Committee. Early acute kidney injury and sepsis: a multicentre evaluation. Crit Care 2008; I2(2): R47. DOI: I0.II86/ cc6863

7. Hoste EA, Clermont G, Kersten A, Venkataraman R, Angus DC, De Bacquer D, et al. RIFLE criteria for acute kidney injury are associated with hospital mortality in critically ill patients: a cohort analysis. Crit Care 2006; I0(3):R73. DOI: I0.II86/ cc4915

8. Khan FG, Ahmed E. Acute renal failure in diabetes mellitus. J Pak Med Assoc 2015 Feb;65(2): I 79-82.

9. Pannu N, Nadim MK. An overview of drug-induced acute kidney injury. Crit Care Med 2008 Apr I;36(4):S2I 6-23. DOI: 10.1097/ccm.0b0|3e318168e375

10. Karimi G, Khoei A, Omidi A, Kalantari M, Babaei J, Taghiabadi E, et al. Protective effect of aqueous and ethanolic extracts of Portulaca oleracea against cisplatin induced nephrotoxicity. Iran J Basic Med Sci

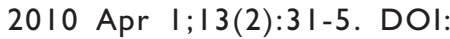
10.22038/IJBMS.2010.5079

II. Yu W, Chen Y, Dubrulle J, Stossi F, Putluri V, Sreekumar A, et al. Cisplatin generates oxidative stress which is accompanied by rapid shifts in central carbon metabolism. Sci Rep 2018 Mar 9;8(I):4306. DOI: I0.1038/s4I598-0I8-22640-y

12. Sharma M, Gupta YK. Chronic treatment with trans resveratrol prevents intracerebroventricular streptozotocin induced cognitive impairment and oxidative stress in rats. Life Sci 2002 II;7I(2I):248998. DOI: $10.1016 / 50024$ 3205(02)02083-0 
13. Malhotra A, Bath S, Elbarbry F. An organ system approach to explore the antioxidative, anti-inflammatory, and cytoprotective actions of resveratrol. Oxid Med Cell Longev 2015;2015:80397I. DOI: 10.1155/ $2015 / 80397 \mid$

14. Al Dera HS. Protective effect of resveratrol against aluminum chloride induced nephrotoxicity in rats. Saudi Med J 2016;37(4):369. DOI: |0.|5537/smj.20।6.4.|36। I

15. Li H, Xia N, Förstermann U. Cardiovascular effects and molecular targets of resveratrol. Nitric Oxide 2012 Feb I5;26(2): I02-I0. DOI: 10.1016/j.niox.201।. 12.006

16. Kitada M, Koya D. Renal protective effects of resveratrol. Oxid Med Cell Longev 2013;2013:568093. DOI: |0.1|55/20|3/568093

17. Sahu BD, Kumar JM, Sistla R. Baicalein, a bioflavonoid, prevents cisplatin-induced acute kidney injury by up-regulating antioxidant defenses and down-regulating the MAPKs and NF-KB pathways. PLoS One. 2015 Jul 29;I0(7):e0I34I39. DOI: $10.137 \mid$ /journal.pone. 0134139

18. Ghosh J, Das J, Manna P, Sil PC.
Acetaminophen induced renal injury via oxidative stress and TNF-alpha production: therapeutic potential of arjunolic acid. Toxicology 2010; 268: 8-I8. DOI: 10.1016/j.tox.2009. II.0II

19. Osman AM, Telity SA, Damanhouri ZA, Al-Harthy SE, Al-Kreathy HM, $\mathrm{R}$ a $\mathrm{m}$ a d a $\mathrm{n}$ W , e $\mathrm{t}$ a I. Chemosensitizing and nephroprotective effect of resveratrol in cisplatin-treated animals. Cancer Cell Int 2015 Dec; I5(I):6. DOI: I0.II86/s| 2935 0|4-0I52-2

20. Sharma S, Anjaneyulu M, Kulkarni SK, Chopra K. Resveratrol, a polyphenolic phytoalexin, attenuates diabetic nephropathy in rats. Pharmacology 2006;76(2):69-75. DOI: 10.1 I59/000089720

21. Holthoff JH, Wang Z, Seely KA, Gokden N, Mayeux PR. Resveratrol improves renal microcirculation, protects the tubular epithelium, and prolongs survival in a mouse model of sepsis-induced acute kidney injury. Kidney Int 2012 Feb 2;8I(4):370-8. DOI: I0.1038/ ki.20I I.347

22. Şener $G$, Tuğtepe $H$, Yüksel $M$, Çetinel Ş, Gedik N, Yeğen BÇ. Resveratrol improves ischemia/ reperfusion-induced oxidative renal injury in rats. Arch Med Res 2006;37(7):822-9. DOI: 10.1016/ j.arcmed.2006.04.003

23. Leonard SS, Xia C, Jiang BH, Stinefelt B, Klandorf $\mathrm{H}$, Harris GK, et al. Resveratrol scavenges reactive oxygen species and effects radicalinduced cellular responses. Biochem Biophys Res Commun 2003;309(4):1017-26. DOI: 10 . 1016/j.bbrc.2003.08.105

24. Chen $\mathrm{KH}$, Hung CC, Hsu HH, Jing $\mathrm{YH}$, Yang CW, Chen JK. Resveratrol ameliorates early diabetic nephropathy associated with suppression of augmented TGF$\beta /$ smad and ERKI/2 signaling in streptozotocin-induced diabetic rats. Chem Biol Interact 2011; 190(I):45-53. DOI: 10.1016/j.cbi. 2011.01 .033

25. Wu L, Zhang Y, Ma X, Zhang N, Qin $G$. The effect of Resveratrol on FoxOl expression in kidneys of diabetic nephropathy rats. Mol Biol Rep 2012;39(9):9085-93. DOI: |0.1007/s| |033-0|2-1780-z

\section{AUTHORS' CONTRIBUTIONS}

Following authors have made substantial contributions to the manuscript as under:

KAM: Study design, acquisition, analysis and interpretation of data, drafting the manuscript, final approval of the version to be published

RAT, SN: Acquisition of data, drafting the manuscript, final approval of the version to be published

AAU, YMN: Analysis and interpretation of data, drafting the manuscript, final approval of the version to be published

NK: Conception, acquisition of data, critical review, final approval of the version to be published

Authors agree to be accountable for all aspects of the work in ensuring that questions related to the accuracy or integrity of any part of the work are appropriately investigated and resolved.

\begin{tabular}{|c|}
\hline CONFLICT OF INTEREST \\
Authors declared no conflict of interest \\
GRANT SUPPORT AND FINANCIAL DISCLOSURE \\
NIL
\end{tabular}

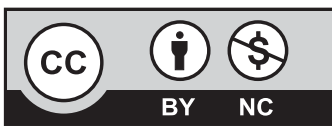

This is an Open Access article distributed under the terms of the Creative Commons Attribution-Non Commercial 2.0 Generic License. 